\title{
Ocular Biometry and Their Correlations with Ocular and Anthropometric Measurements Among Ethiopian Adults
}

This article was published in the following Dove Press journal:

Clinical Ophthalmology

\section{Girum W Gessesse (DD \\ Asrat Sime Debela \\ Dereje Hayilu Anbesse}

Department of Ophthalmology, St. Paul's Hospital Millennium Medical College, Addis Ababa, Ethiopia
Correspondence: Dereje Hayilu Anbesse POB: $127 \mid$

Tel +251910046930

Email dereje.hayilu@sphmmc.edu.et
Purpose: To determine the average values of ocular biometry dimensions and investigate their inter-correlations and their association with anthropometric measurements among Ethiopian adults with healthy eyes.

Methods: A cross-sectional study was undertaken from June 2018 to July 2019. A total of 400 eyes of 200 subjects were included in the study. Univariable and multivariable linear regression were used to determine the association of demographic variables (age and sex) and anthropometric parameters (height, weight and BMI) with ocular biometric indices.

Results: The mean age was $40.31 \pm 11.39$ with a range from 18 to 69 years. The mean (SD) of horizontal corneal diameter, average corneal refractive power, anterior chamber depth (ACD), lens thickness (LT) and axial length (AL) were 11.45 (0.89) mm, 43.94 (9.78) diopter, $2.91(0.43) \mathrm{mm}, 4.29(0.55) \mathrm{mm}$ and $22.96(0.82) \mathrm{mm}$, respectively. Age had a negative correlation with $\operatorname{ACD}(\mathrm{r}=-0.196, p=<0.001)$ and positive correlation with lens thickness $(\mathrm{r}=0.324, p<0.001)$. Height had a positive correlation with ACD $(r=0.114$, $p=0.023)$ and $\operatorname{LT}(\mathrm{r}=0.206, \mathrm{p}=<0.001)$ while negative correlation with LT $(\mathrm{r}=-0.129$, $p=0.01)$. In the multivariate linear regression, age $(-0.009(-0.013,-0.05), p$-value $<0.001)$ and sex $(0.104(0.01,0.198), p$-value $=0.03)$ had a significant association with ACD and only gender $(0.478(0.302,0.654), p$-value $<0.001)$ had a statistically significant association with lens thickness.

Conclusion: This study determined the normative values for ocular biometric parameters among Ethiopian adults for the first time. Age, gender and height were associated with biometric indices. AL was significantly positively correlated with ACD and negatively correlated with LT. There was a negative correlation between LT and both AL and ACD.

Keywords-: biometry, anterior chamber depth, anthropometry, glaucoma

\section{Introduction}

Anterior chamber depth (ACD), lens thickness, axial length (AL) and corneal radius of curvature are essential parameters associated with the occurrence of ocular diseases such as primary angle closure glaucoma (PACG). The prevalence of PACG is said to be low in Africa as compared with Asians and Caucasians. In a study among eye clinic patients in Nigeria, only $9.2 \%$ were found to have angle closure with or without glaucoma ${ }^{1}$ while a population-based study among an Indigenous African in Southwestern Nigeria found PACG in only $0.2 \%$ of the population. ${ }^{2}$ However in two clinic-basedstudies in South West Ethiopia, PACG was identified in $21 \%^{3}$ and $17.3 \%$ of patients. ${ }^{4}$ These are the highest reported 
proportion of angle closure glaucoma in Africa. Therefore, there is a need to study the variations of ocular biometry factors among Ethiopian adults.

Various studies have shown that ocular biometry is correlated with systemic biometric parameters such as age, gender, body height, body weight, and body mass index (BMI). A population-based study among Black South Africans indicated that AL and ACD decreased with age, while lens thickness increased with age and all biometric indices directly correlated with the male gender and height. ${ }^{5}$ Another study from Nigeria showed body height to be independently associated with ocular AL and ACD while the body weight and BMI were not independently associated with any of the ocular biometric indices studied. ${ }^{6}$

A possible association between central or limbal ACD and adult anthropometry has been described in several population-based studies. It was reported that there is a tendency for taller persons to have longer AL, deeper ACD, longer vitreous cavity distance, flatter corneas and thinner lenses, compared with shorter persons of similar weight, age, gender, and socioeconomic status. ${ }^{7}$ A significant association between shallower limbal ACD and shorter body stature was also found in a study from Beijing. ${ }^{8}$ Similarly, in the rural Central Indian population, a shallow anterior chamber was associated with higher age, female gender, short body stature, hyperopia, thick lens and shorter axial length. ${ }^{9}$ In a study among Chinese adults aged 50 years and older, lower BMI and weight were associated with significantly greater odds of narrow angle after adjusting for age, education, axial ocular biometric measures, and height. ${ }^{10}$

Normative data of the ocular biometry and its associations with other ocular and general parameters have not systematically been assessed yet for the population of Ethiopia. Therefore, we believe that this study will serve as baseline evidence on these important clinical parameters.

This study was carried out with the main objective of determining the average values of ocular biometry dimensions among Ethiopian adults with healthy eyes and investigates their inter-correlations and their association with anthropometric measurements.

\section{Materials and Methods}

\section{Study Setting and Population}

This was a cross-sectional study undertaken between June 2018 and July 2019 at the Department of
Ophthalmology, St. Paul's Hospital Millennium Medical College (SPHMMC), Addis Ababa, Ethiopia. SPHMMC is a tertiary center for health care, training, and research.

The study subjects were selected by using random sampling among new individuals attending the ophthalmology department seeking eye care service or were attendants of patients. A total of 400 eyes of 200 subjects were included in the study. Inclusion criteria included age 18 years or above with normal intraocular pressure (IOP) and no evidence of glaucomatous optic neuropathy. We excluded subjects with any optic neuropathy (glaucomatous, traumatic, ischemic), a history of intraocular surgery, corneal pathology, pseudophakia or aphakia or patients with significant cataract obscuring view of fundus. Ethical clearance was obtained from the Institutional Review Board (IRB) of SPHMMC. All participants provided oral informed consent, and this study was conducted in accordance with the Declaration of Helsinki.

\section{Examination and Procedures}

A comprehensive clinical history and eye examination were performed that included visual acuity measurement, slit lamp examination, stereoscopic optic disc examination using a +90-diopter lens under Slit Lamp Biomicroscope and IOP measurement using Goldmann applanation tonometer.

Autokeratorefracometry was performed using Autrefractor VISUREF 150 (Carl Zeiss Meditec AG, Jena Germany) for each subject. Ocular biometry parameters such as anterior chamber depth, lens thickness and axial length were measured for each eye of all subjects using a compact touch AB Scan Biometer (Quantel medical, cournon, d'Auvergne, France). The examinations were performed up to five times each, and the mean values taken.

Height was measured with a tape measure with the subject standing up without shoes and recorded in centimeters $(\mathrm{cm})$.

\section{Statistical Analysis}

The raw data was entered into Epi data version 3.1 and exported to and analyzed using SPSS version 20. Frequency was determined for socio-demographic variables such as age and gender. Pearson correlation analysis was done to determine the relationship between ocular and anthropometric parameters. Univariable and multivariable linear regression was also used to determine the association of demographic variables (age and sex) and anthropometric parameters (height, weight, and BMI) with 


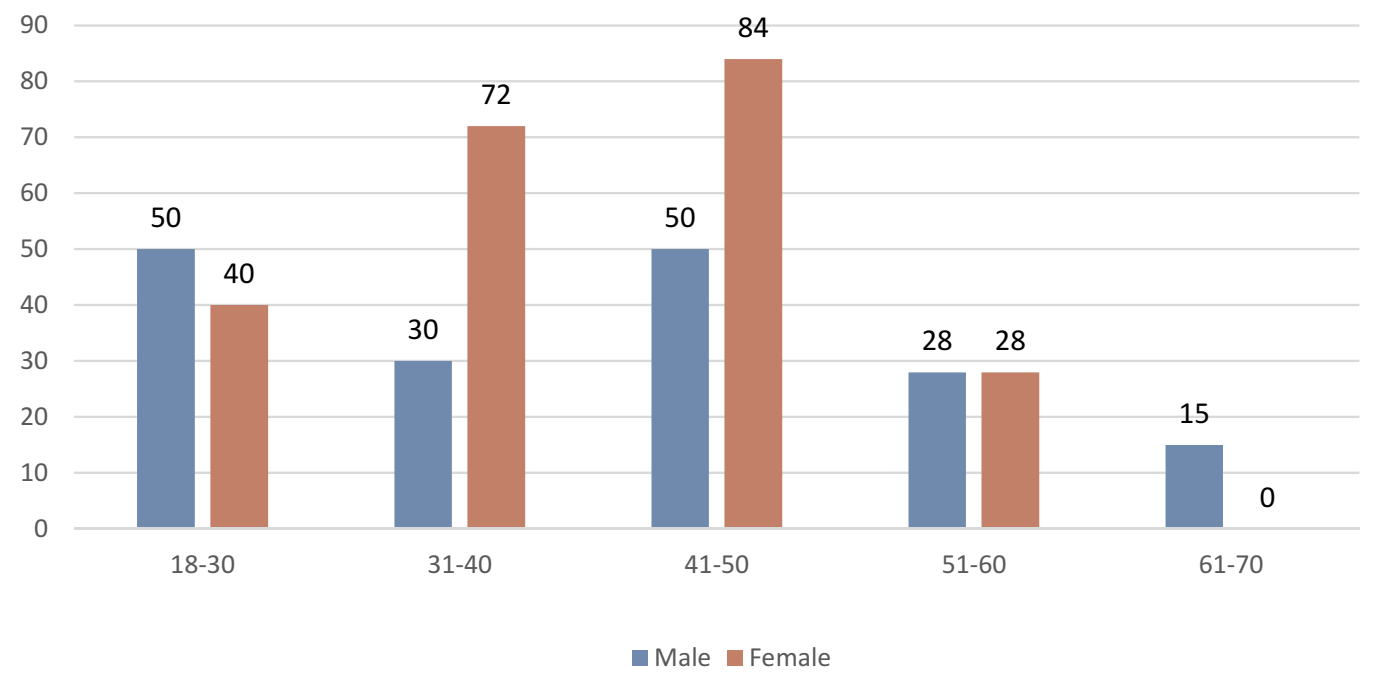

Figure I Age and gender distributions of study participants, 2020.

ocular biometric indices. Statistical significance was maintained at a $p$-value less than 0.05 .

\section{Results}

A total of 400 eyes of 200 subjects were included in the study. The mean age was $40.31 \pm 11.39$ with a range from 18 to 69 years and about $220(55 \%)$ of them were female participants. More than one third 172 (43\%) of the study participants were from Oromo ethnic group and about 118 (29.5\%) were Amhara and 72 (18\%) were Gurage participants. A total of 28 or $7 \%$ participants had been diagnosed with diabetic mellitus and/or systemic hypertension (Figure 1).

The mean age ( \pm SD) of study subjects was 41.27 ( \pm 13.22) years among males and 39.54 ( \pm 9.60) among females. With respect to gender, the difference in weight, height and BMI were significantly observed with a $p$-value less than 0.001 . Vertical and horizontal corneal diameter which was measured in $\mathrm{mm}$, average corneal refractive power in dioptric value, ACD and AL were significantly different between male and females with a $p$-value less than 0.01 (Table 1).

Correlational analyses indicated that, age has anegative correlation with ACD ( $\mathrm{r}=-0.196, p=<0.001)$ and positive correlation with lens thickness $(\mathrm{r}=0.324, p<0.001)$. As age increased, ACD decreased and LT increased. Height had a positive correlation with vertical $(\mathrm{r}=0.128, p=0.01)$ and horizontal $(\mathrm{r}=0.182, p<0.001)$ corneal diameter, $\mathrm{ACD}(\mathrm{r}=0.114$, $p=0.023)$ and $\mathrm{AL}(\mathrm{r}=0.206, p=<0.001)$ while a negative correlation with lens thickness $(\mathrm{r}=-0.129, p=0.01)$. There was a positive relationship between BMI and lens thickness

Table I Mean and Standard Deviation of Socio-Demographic Variables in Terms Gender Among Participants, 2020

\begin{tabular}{|c|c|c|c|c|}
\hline \multirow[t]{2}{*}{ Variable } & \multirow{2}{*}{$\begin{array}{l}\text { Total }(n=400) \\
\text { Mean (SD) }\end{array}$} & Male $(n=180)$ & Female $(n=220)$ & $p$-value \\
\hline & & Mean (SD) & Mean (SD) & \\
\hline Age & 40.31 (11.39) & $41.269(13.22)$ & $39.54(9.60)$ & 0.133 \\
\hline Weight in $\mathrm{kg}$ & $64.00(10.98)$ & $67.22(11.95)$ & $61.37(9.37)$ & $<0.001$ \\
\hline Height in $\mathrm{m}$ & $1.66(0.07)$ & $1.70(0.065)$ & $1.63(0.07)$ & $<0.001$ \\
\hline BMI & $23.10(3.73)$ & $23.13(3.61)$ & $23.07(3.84)$ & 0.873 \\
\hline IOP & $14.94(2.85)$ & $14.95(2.87)$ & $14.92(2.84)$ & 0.929 \\
\hline Vertical corneal diameter & $10.66(0.77)$ & $10.84(0.68)$ & $10.52(0.8 \mathrm{I})$ & $<0.001$ \\
\hline Horizontal corneal diameter & II.45 (0.89) & II.67 (0.6I) & II.27 (I.03) & $<0.001$ \\
\hline Average corneal refractive power & $43.94(9.78)$ & $43.30(1.28)$ & $44.46(3.12)$ & 0.242 \\
\hline AC depth & $2.91(0.43)$ & $2.98(0.45)$ & $2.85(0.40)$ & 0.003 \\
\hline Lens thickness & $4.29(0.55)$ & $4.28(0.62)$ & $4.29(0.48)$ & 0.873 \\
\hline Axial length & $22.96(0.82)$ & $23.25(0.88)$ & $22.71(0.69)$ & $<0.001$ \\
\hline
\end{tabular}

Abbreviations: BMI, body mass index; AC, anterior chamber; IOP, intra ocular pressure. 
Table 2 Correlations of Demographic Variables with Biometric Indices of Study Participants, 2020

\begin{tabular}{|c|c|c|c|c|c|c|}
\hline Variable & $\begin{array}{l}\text { Vertical Corneal } \\
\text { Diameter }\end{array}$ & $\begin{array}{l}\text { Horizontal Corneal } \\
\text { Diameter }\end{array}$ & $\begin{array}{l}\text { Average Corneal } \\
\text { Refractive Power }\end{array}$ & AC Depth & $\begin{array}{l}\text { Lens } \\
\text { Thickness }\end{array}$ & Axial Length \\
\hline \multicolumn{7}{|l|}{ Age } \\
\hline$r(p)$ & $-0.022(0.660)$ & $-0.062(0.213)$ & $-0.014(0.781)$ & $-0.196(0.000)$ & $0.324(0.000)$ & $0.030(0.556)$ \\
\hline Weight & & & & & & \\
\hline$r(p)$ & $0.012(0.816)$ & $0.036(0.470)$ & $0.046(0.357)$ & $0.074(0.14 I)$ & $0.067(0.182)$ & $0.082(0.103)$ \\
\hline \multicolumn{7}{|l|}{ Height } \\
\hline$r(p)$ & $0.128(0.01)$ & $0.182(0.000)$ & $-0.072(0.15 \mathrm{I})$ & $0.114(0.023)$ & $-0.129(0.010)$ & $0.206(0.000)$ \\
\hline \multicolumn{7}{|l|}{ BMI } \\
\hline$r(p)$ & $-0.059(0.237)$ & $-0.06 \mathrm{I}(0.226)$ & $0.097(0.053)$ & $0.011(0.822)$ & $0.144(0.004)$ & $-0.038(0.449)$ \\
\hline \multicolumn{7}{|l|}{ IOP } \\
\hline$r(p)$ & $-0.011(0.831)$ & $0.003(0.954)$ & $0.030(0.552)$ & $-0.014(0.776)$ & $0.060(0.229)$ & $0.075(0.134)$ \\
\hline
\end{tabular}

Abbreviations: $r$, Pearson correlation coefficient, p, p-value, BMI, body mass index; AC, anterior chamber; IOP, intra ocular pressure.

$(\mathrm{r}=0.144, p=0.004)$; there was no statistically significant relationship between weight and biometric indices (Table 2).

In the linear regression analysis, age of the participants had a negative relationship with ACD. For every 1 year increment of age the anterior chamber depth was reduced by $0.007 \mathrm{~mm}$ (Figure 2). Height had a positive relationship with ACD because as height increased by $1 \mathrm{~cm}$, the depth of the anterior chamber was increased by $0.0066 \mathrm{~mm}$ (Figure 3).

In the univariate linear regression analysis, age, gender, and height were significantly associated with ACD. However, only age $(-0.009(-0.013,-0.05), p$-value $<0.001)$ and gender $(0.104(0.01,0.198), p$-value $=0.03)$ had a significant association in the multivariable linear

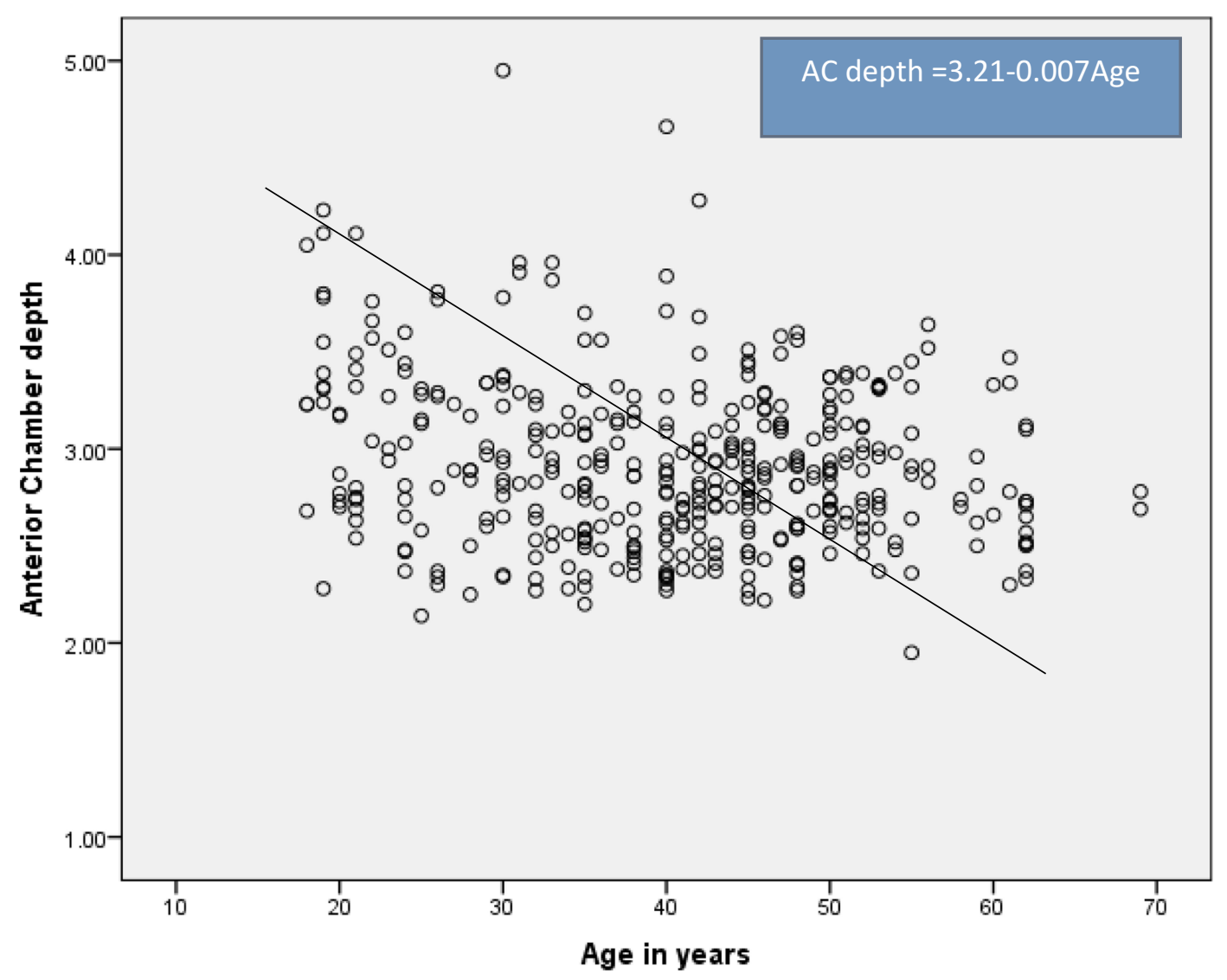

Figure 2 Relationship of anterior chamber depth and age among study subjects, 2020. 
regression. With respect to LT; age, height and BMI had a significant association in the univariable analysis and only age $(0.016(0.011,0.02), p$-value $<0.001)$ persisted after adjustment. Gender and height were significantly associated with $\mathrm{AL}$ in the univariable linear regression and only gender $(0.478(0.302,0.654), p$-value $<0.001)$ was statistically significant in the multivariable linear regression (Table 3 ).

\section{Discussion}

Ocular biometric parameters can be influenced by many factors including race and genetics. Normative data of the ocular parameters have not systematically been assessed yet for the population of Ethiopia. This study tried to assess the normative ocular biometric features of adult Ethiopians and their associations with ocular and anthropometric measures.

The mean ACD in this study was found to be $2.91 \pm$ $0.43 \mathrm{~mm}$; this is similar to a study from the USA $(2.96 \mathrm{~mm}$, among 29-90 year olds), ${ }^{11}$ Singapore (2.90 mm among 40-81 year olds) ${ }^{12}$ and Myanmar (2.82 mm among 40 years and above age). ${ }^{13}$ This finding is, however, smaller than the one reported among blacks in South Africa $(3.21 \mathrm{~mm})^{5}$ and Nigeria (3.3 $\mathrm{mm}$ for males and $3.24 \mathrm{~mm}$ for women) ${ }^{6}$ but is larger than those reported from the People's Republic of China (2.67mm, among 50-93 year olds) ${ }^{14}$ and Iran (2.62 mm, among 40-64 year olds). ${ }^{15}$ The shallower ACD in our study may explain the higher prevalence of ACG shown in our clinic-based studies as compared with other African reports.

Using the regression coefficients of analysis, the mean ACD decreased by $0.009 \mathrm{~mm}$ for every 1 year increment of age (Figure 2). A decrease in ACD with increase in age is similar to other studies ${ }^{5,15-17}$ and this is explained by thickening of the crystalline lens with aging.

Female gender was also associated with having shallower ACD than males. This is also in keeping with other studies $^{5,15,18}$ and confirms the long-term belief that females have lower ACD measurements than males. This association remained statistically significant after adjustment for body height, weight and body mass index. Many studies have shown the higher occurrence of angle closure glaucoma among females compared to males. ${ }^{19}$

The finding of the association between shallow ACD and short body stature in this study is interesting. As height increased by $1 \mathrm{~cm}$, ACD increased by $0.0066 \mathrm{~mm}$. Many other studies have shown a similar association. ${ }^{20}$

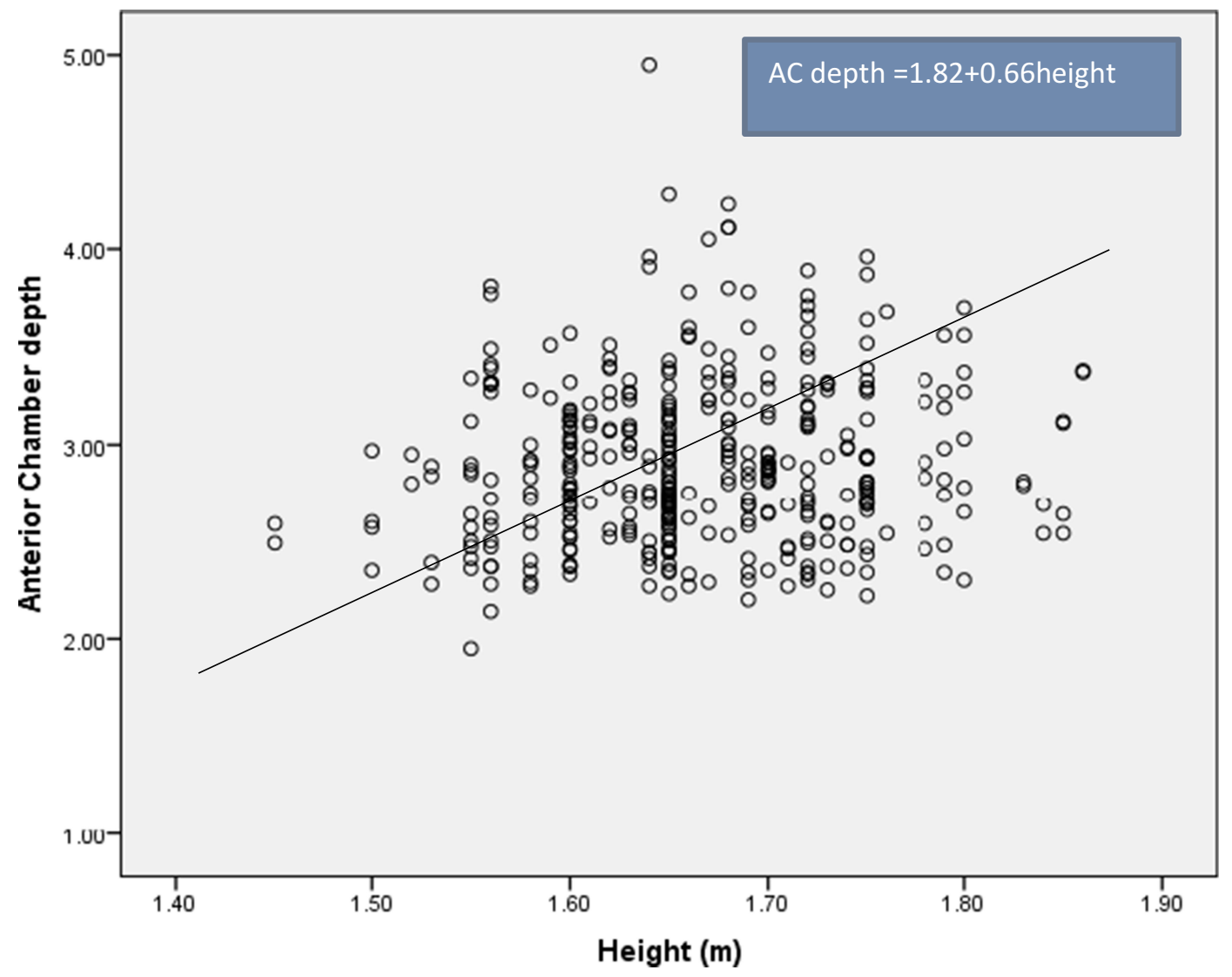

Figure 3 Relationship of anterior chamber depth and height among study subjects, 2020. 
Table 3 Association of Demographic Variables with Biometric Indices Among Study Participants Using Linear Regression, 2020

\begin{tabular}{|c|c|c|c|c|}
\hline \multirow[t]{3}{*}{ Variable } & \multicolumn{2}{|l|}{ Non-adjusted } & \multicolumn{2}{|l|}{ Adjusted } \\
\hline & $\beta$ 95\% Cl & p-value & $\beta$ 95\% Cl & p-value \\
\hline & \multicolumn{2}{|l|}{ Ac depth } & \multicolumn{2}{|c|}{ Ac depth (adjusted for Al, LT) } \\
\hline Age per I year & $-0.007(-0.011,-0.004)$ & $<0.001$ & $-0.009(-0.013,-0.005)$ & $<0.001$ \\
\hline Gender (male) & $0.129(0.045,0.213)$ & 0.003 & $0.104(0.01,0.198)$ & 0.03 \\
\hline Height per I cm & $0.658(0.091,1.225)$ & 0.023 & & \\
\hline Weight per I kg & $0.003(-0.00 \mathrm{I}, 0.007)$ & 0.141 & & \\
\hline \multirow[t]{2}{*}{ BMI } & $0.001(-0.01,0.013)$ & 0.822 & & \\
\hline & \multicolumn{2}{|l|}{ Lens thickness } & \multicolumn{2}{|c|}{ Lens thickness (adjusted for $A C D, A L$ ) } \\
\hline Age per I year & $0.016(0.011,0.020)$ & $<0.001$ & $0.016(0.011,0.02)$ & $<0.001$ \\
\hline Gender (male) & $-0.009(-0.117,0.099)$ & 0.873 & & \\
\hline Height per I cm & $-0.952(-1.670,-0.233)$ & 0.01 & & \\
\hline Weight per I kg & $0.003(-0.002,0.008)$ & 0.182 & & \\
\hline \multirow[t]{2}{*}{ BMI } & $0.021(0.007,0.035)$ & 0.004 & & \\
\hline & \multicolumn{2}{|l|}{ Axial length } & \multicolumn{2}{|c|}{ Axial length (adjusted for ACD, LT) } \\
\hline Age per I year & $0.002(-0.005,0.009)$ & 0.556 & & \\
\hline Gender (male) & $0.535(0.38 \mathrm{I}, 0.689)$ & $<0.001$ & $0.478(0.302,0.654)$ & $<0.001$ \\
\hline Height per I cm & $2.285(1.218,3.353)$ & $<0.001$ & & \\
\hline Weight per I kg & $0.006(-0.001,0.013)$ & 0.103 & & \\
\hline BMI & $-0.008(-0.03,0.013)$ & 0.449 & & \\
\hline
\end{tabular}

However, in multivariable linear regression, only age $(p$-value $<0.001)$ and female sex $(p$-value $=0.03)$ had a statistically significant association with ACD.

The average lens thickness in this study was 4.29 $( \pm 0.55) \mathrm{mm}$. In the study among black south Africans, the mean LT was $3.69( \pm 0.25) \mathrm{mm}$ while a study comparing ethnic differences in lens parameters found the average measurements in whites $4.52(0.46) \mathrm{mm}$, African American $4.48( \pm 0.54) \mathrm{mm}$, Asians $4.60( \pm 0.46) \mathrm{mm}$, and Hispanics $4.53( \pm 0.44) \mathrm{mm}^{21}$ In our study, age, height, and BMI have a significant association in the univariable analysis but only age ( $p$-value $<0.001)$ persisted after adjustment. This is in keeping with other studies. ${ }^{14,17}$

The increase in LT may be attributed to greater density of the lens due to increased protein fiber formation and the increase in LT may be a contributing factor for the decrease in ACD with age.

The mean AL in this study of $22.96 \mathrm{~mm}$ is similar to that $(23.05 \mathrm{~mm} \pm 0.98 \mathrm{~mm})$ found in black South Africans but slightly shorter than that $(23.57 \mathrm{~mm})$ obtained in another Nigerian study. A study among older white adults in the US found mean AL to be $23.69 \mathrm{~mm}^{22}$ In our study, gender and height were significantly associated with axial length in the univariable linear regression while only gender $(0.478(0.302,0.654), p$-value $<0.001)$ remained statistically significant in the multivariable linear regression. In the above study from the USA, larger eyes were observed in men (vs women) and in taller persons but adjustment for height accounted for all gender differences.

Horizontal corneal diameter (HCD) of $11.45 \pm$ $0.89 \mathrm{~mm}$ is similar to the $11.39 \pm 0.69 \mathrm{~mm}$ reported from Nigeria. ${ }^{23}$ Males had significantly larger HCD than females $(p=0.03)$. Subjects in older age groups had smaller HCD.

The major limitation in this study is the cross-sectional design, which limits evaluation of change in these measures with age; longitudinal data are needed for this. The differences in the age groups included and methods used to determine the biometric data among studies may also be a factor in the variations in the findings between different studies.

\section{Conclusion}

This study is the first of its kind to determine the normative values for AL, ACD and LT in Ethiopian adults. Age, gender, and height were associated with biometric indices. The mean ACD in this study was shallower than those reported from other African countries. While there was 
a positive correlation between $\mathrm{AL}$ and $\mathrm{ACD}$, there was a negative correlation between LT and both AL and ACD. These biometric data may provide baseline clinical information on ocular biometric measures among Ethiopians.

\section{Acknowledgments}

We would like to express our gratitude to the participants of this study for giving their consent to participate in the study. We also extend our gratitude to IRB of St. Paul's Hospital Millennium Medical College for giving us ethical clearance and permission to conduct the study.

\section{Disclosure}

The authors report no conflicts of interest in this work.

\section{References}

1. Olawoye OO, Sarimiye TS. Is angle closure glaucoma a problem in Nigeria? Niger J Clin Pract. 2014;17:159-162. doi:10.4103/11193077.127425

2. Ashaye A, Ashaolu O, Komolafe O, et al. Prevalence and types of glaucoma among an indigenous African population in southwestern Nigeria. Invest Ophthalmol Vis Sci. 2013;54:7410-7416. doi:10.1167/ iovs. 13-12698

3. Tenkir A, Solomon B, Amare D. Glaucoma subtypes in Ethiopia clinic patients. $J$ Glaucoma. 2013;22:110-116. doi:10.1097 IJG.0b013e31823298c8

4. Tolesa K, Gessesse GW. Central corneal thickness in newly diagnosed glaucoma patients in South West Ethiopia: a cross-sectional study. BMC Ophthalmol. 2016;16:152.

5. Mashige KP, Oduntan OA. Axial length, anterior chamber depth and lens thickness: their intercorrelations in black South Africans. Afr Vision Eye Health. 2017;76(1):1-7.

6. Badmus SA, Ajaiyeoba AI, Adegbehingbe BO, Onakpoya $\mathrm{OH}$, Adeoye AO. Associations between ocular biometry and anthropometric measurements in a Nigerian population. Niger Postgrad Med J. 2016;23:127-131. doi:10.4103/1117-1936.190341

7. Wong TY, Foster PJ, Johnson GJ, et al. The relationship between ocular dimensions and refraction with adult stature: the Tanjong Pagar Survey. Invest Ophthalmol Vis Sci. 2001;42:1237-1242.

8. Xu L, Li JJ, Xia CR, et al. Anterior chamber depth correlated with anthropomorphic measurements: the Beijing Eye Study. Eye (Lond). 2009;23:632-634.

9. Jonas JB, Nangia V, Gupta R, et al. Anterior chamber depth and its associations with ocular and general parameters in adults. Clin Experiment Ophthalmol. 2012;40:550-556. doi:10.1111/j.14429071.2011.02748.x
10. Jiang $\mathrm{Y}, \mathrm{He} \mathrm{M}$, Friedman DS, et al. Associations between narrow angle and adult anthropometry: the Liwan eye study. Ophthalmic Epidemiol. 2014;21(3):184-189. doi:10.3109/09286586.2014.903500

11. Jivrajka R, Shammas MC, Boenzi T, Swearingen M, Shammas HJ. Variability of axial length, anterior chamber depth, and lens thickness in the cataractous eye. J Cataract Refract Surg. 2008;34:289-294. doi:10.1016/j.jcrs.2007.10.015

12. Wong TY, Foster PJ, Ng TP, Tielsch JM, Johnson GJ, Seah SK. Variations in ocular biometry in an adult Chinese population in Singapore: the Tanjong Pagar Survey. Invest Ophthalmol Vis Sci. 2001;42:73-80.

13. Warrier S, Wu HM, Newland HS, et al. Ocular biometry and determinants of refractive error in rural Myanmar: the Meiktila eye study. Br J Ophthalmol. 2008;92:1591-1594.

14. He M, Huang W, Li Y, Zheng Y, Yin Q, Foster PJ. Refractive error and biometry in older Chinese adults: the Liwan eye study. Invest Ophthalmol Vis Sci. 2009;50:5130-5136. doi:10.1167/iovs.09-3455

15. Hashemi H, Khabazkhoob M, Miraftab M, et al. The distribution of axial length, anterior chamber depth, lens thickness, and vitreous chamber depth in an adult population of Shahroud, Iran. BMC Ophthalmol. 2012;12:50.

16. He M, Huang W, Zheng Y, Alsbirk PH, Foster PJ. Anterior chamber depth in elderly Chinese: the Liwan eye study. Ophthalmology. 2008;115:1286-1290. doi:10.1016/j.ophtha.2007.12.003

17. Foster PJ, Alsbirk PH, Baasanhu J, Munkhbayar D, Uranchimeg D, Johnson GJ. Anterior chamber depth in Mongolians: variation with age, sex, and method of measurement. Am $J$ Ophthalmol. 1997;124:53-60. doi:10.1016/S0002-9394(14)71644-7

18. Alsbirk PH. Anterior chamber of the eye: a genetic and anthropological study in Greenland eskimos. Hum Hered. 1975;25:418-427. doi:10.1159/000152755

19. Vijaya L, George R, Arvind H, et al. Prevalence of primary angle-closure disease in an urban south Indian population and comparison with a rural population. The Chennai glaucoma study. Ophthalmology. 2008;115:655-660. doi:10.1016/j. ophtha.2007.05.034

20. Xu L, Li J, Wang Y, Jonas JB. Anterior chamber depth and chamber angle and their associations with ocular and general parameters: the Beijing eye study. Am $J$ Ophthalmol. 2008;145:929-936. doi:10.1016/j.ajo.2008.01.004

21. Wang D, Amoozgar B, Porco T, Wang Z, Lin SC. Ethnic differences in lens parameters measured by ocular biometry in a cataract surgery population. PLoS One. 2017;12(6):e0179836. doi:10.1371/journal. pone. 0179836

22. Lee KE, Klein BE, Klein R, Quandt Z, Wong TY. Association of age, stature, and education with ocular dimensions in an older white population. Arch Ophthalmol. 2009;127(1):88-93. doi:10.1001/ archophthalmol.2008.521

23. Iyamu E, Osuobeni E. Age, gender, corneal diameter, corneal curvature and central corneal thickness in Nigerians with normal intra ocular pressure. J Optom. 2012;5:87-97. doi:10.1016/j. optom.2012.02.001
Clinical Ophthalmology

\section{Publish your work in this journal}

Clinical Ophthalmology is an international, peer-reviewed journal covering all subspecialties within ophthalmology. Key topics include: Optometry; Visual science; Pharmacology and drug therapy in eye diseases; Basic Sciences; Primary and Secondary eye care; Patient Safety and Quality of Care Improvements. This journal is indexed on PubMed
Central and CAS, and is the official journal of The Society of Clinical Ophthalmology (SCO). The manuscript management system is completely online and includes a very quick and fair peer-review system, which is all easy to use. Visit http://www.dovepress.com/ testimonials.php to read real quotes from published authors. 